\title{
Long-term Outcomes of Immediate Versus Delayed Nephroureterectomy for Upper Tract Urothelial Carcinoma
}

Adam J. Gadzinski, B.S., William W. Roberts, M.D., Gary J. Faerber, M.D., and J. Stuart Wolf, Jr., M.D., FACS

\begin{abstract}
Purpose: To compare immediate nephroureterectomy with delayed nephroureterectomy after a trial of nephronsparing endoscopic surgery in patients who were treated initially at our institution from 1996 to 2004 for upper tract urothelial carcinoma. Patients were monitored for upper tract recurrences, metastases, cancer-specific and overall survival. Survival outcomes and perioperative measurements were compared between treatment groups. Results: Of 73 patients, 62 underwent immediate nephroureterectomy and 11 proceeded to nephroureterectomy after failed endoscopic management. Mean follow-up for all patients was 58 months and 75 months for patients who were alive at last follow-up. Patients treated initially with endoscopy averaged a surveillance procedure every 3.7 months and had a median delay to nephroureterectomy of 10 months. Perioperative measurements at time of nephroureterectomy did not differ between groups. Overall survival 5 years from initial resection in the delayed group and from nephroureterectomy in the immediate group was $64 \%$ and $59 \%$, respectively; the corresponding 5-year cancer-specific and metastasis-free survival estimates were $91 \%$ vs $80 \%$ and $77 \%$ vs $73 \%$, respectively $(P>0.05)$. Pathologic progression from low to high-grade occurred in three of seven patients from the delayed group.

Conclusions: Failure of endoscopic management necessitating nephroureterectomy does not appear to affect survival outcomes compared with immediate nephroureterectomy in patients with upper tract urothelial carcinoma. A trial of endoscopic management can be considered in patients with low-grade disease and a normal contralateral kidney. Endoscopy is a viable option when there are imperative indications for nephron sparing in the setting of high-grade disease.
\end{abstract}

\section{Introduction}

$\mathbf{U}$ PPER TRACT UROTHELIAL CARCINOMA (UTUC) is a rare disease, accounting for approximately $5 \%$ of all renal and urothelial tumors. ${ }^{1}$ Radical nephroureterectomy (NUx) with bladder cuff remains the gold-standard treatment. ${ }^{2}$ The initial development and use of ureteroscopic ${ }^{3}$ and percutaneous ${ }^{4}$ techniques in UTUC provided reasonable alternatives to NUx in patients with imperative indications for nephron sparing. ${ }^{5}$ With further refinement and standardization of the techniques, we and others have shown that endoscopic management can be successfully applied to patients with a normal contralateral kidney with limited low-grade disease. ${ }^{6-11}$ Despite this success, $19 \%$ to $33 \%$ of patients experience disease progression necessitating NUx. ${ }^{6-11}$

We recently reported long-term results of endoscopic management and hand-assisted laparoscopic (HAL) NUx in 96 renal units with UTUC. ${ }^{7}$ Of the 34 renal units with initial endoscopic management, 11 (32\%) later needed NUx. We report on these patients who progressed to NUx after a trial of nephron-sparing management, and exclusively compare them with patients who underwent immediate NUx. Our goal is to elucidate whether patients who eventually progress to NUx are adversely affected by the initial decision to pursue endoscopic management of UTUC.

\section{Patients and Methods}

With Institutional Review Board approval, we identified 73 patients with clinically localized UTUC treated initially at our institution from 1996 through 2004 who underwent NUx. A subset of these patients initially underwent primary endoscopic management and delayed NUx. No patients received neoadjuvant chemotherapy.

\section{Endoscopy}

All delayed NUx patients initially pursued endoscopic management with curative intent. We initially used ureteroscopy (URS) in most cases, as described previously. ${ }^{12}$ UTUC was confirmed with biopsy in most cases and with cytology from saline barbotage in the remaining. For tumors that could not be completely ablated ureteroscopically, a percutaneous

Department of Urology, University of Michigan, Ann Arbor, Michigan. 
approach with a $24 \mathrm{~F}$ resectoscope and flexible nephroscope was used.

After initial successful tumor ablation, patients were counseled regarding continued endoscopic management vs NUx. UTUC grade, size, and multifocality were considered along with the patient's medical condition and indications for nephron sparing. Patients were informed of the estimated need for additional procedures with each approach, likelihood of recurrences, disease progression, impact on renal function, and overall quality of life. Patients who declined endoscopic management were included in the immediate NUx group. Those who pursued endoscopic management were required to have complete endoscopic tumor resection and agree to regular URS at variable intervals determined by tumor characteristics and recurrence patterns. ${ }^{12}$ Tumor recurrences were first managed with URS, but percutaneous nephroscopy was used, if needed. After each recurrence, the decision for continued endoscopic management vs proceeding to NUx was reconsidered. When nephron-sparing management was abandoned, NUx was preferentially performed with HAL surgery (HALS), when possible.

\section{Immediate nephroureterectomy}

Patients with initial disease not amendable to nephronsparing management and those who declined endoscopic surveillance underwent NUx as described previously. ${ }^{13}$ Briefly, we used transperitoneal HALS with a variety of distal ureter management techniques. Subsequent bladder surveillance was first performed with flexible office cytoscopy at 3 months and then at variable intervals, depending on tumor characteristics and recurrence patterns.

\section{Systemic surveillance}

Systemic surveillance was conducted in all patients every 6 to 12 months, depending on tumor characteristics and recurrence patterns, using abdominal-pelvic CT or MRI, plain radiography, or CT chest imaging, and complete blood cell count and complete serum chemistry.

\section{Data analysis}

The 1998 World Health Organization classification was used for tumor grade assignment. Previous studies have shown that endoscopic biopsy is accurate at determining grade, thus allowing for initial disease classification in the delayed patients. ${ }^{14,15} \mathrm{NUx}$ specimens were pathologically staged using the Tumor-Node-Metastasis system. Staging of endoscopic biopsies was not conducted. For classification of grade progression in patients with delayed NUx, pathologic grade from initial endoscopic resection was compared with final pathology determination at the time of NUx. Only patients with low-grade disease at initial resection were eligible for grade progression. Patients with initial high-grade disease were considered maximally progressed at diagnosis, and thus excluded from this subset analysis. Preoperative medical records were used to gather patient data including age, sex, body mass index, American Society of Anethesiologists score, and any previous occurrence of bladder tumors before discovery of UTUC. Age-adjusted Charlson comorbidity index (CCI) excluding the diagnosis of urothelial carcinoma was calculated. ${ }^{16}$
For survival measurements, the starting point was the date of initial complete tumor resection, whether by endoscopy in the delayed group or NUx in the immediate group. In the delayed group, URS was used to determine local upper tract recurrence. Event time for local recurrence and systemic spread was defined as first documented date of recurrence or metastasis. The last disease-free surveillance date determined the censored time in patients without recurrence or metastasis. Overall survival (OS) and cancer-specific survival (CSS) data were obtained by contacting referring physicians, patients, and families, and by querying the University of Michigan Cancer Registry and the Social Security Death Index. In most cases, death from UTUC vs other causes was determined from these data sources.

Intraoperative complications from both endoscopy and NUx were recorded. Major intraoperative complications necessitated significant additional surgical or medical intervention. Postoperative complications within 30 days and any later complications directly related to the procedure were graded with the modified Clavien classification system. ${ }^{17}$ For comparison of NUx operative data between study groups, only patients who underwent the HALS technique were included.

Statistical analysis was performed with commercial software. A $P$ value $<0.05$ was considered significant. For comparisons of demographic, pathologic, and operative data between study groups, we used the Mann-Whitney $U$ test for continuous variables and chi-square or Fisher exact test for categorical variables. Survival estimates were obtained from Kaplan-Meier curves, and the survival data were compared with the log-rank test.

\section{Results}

Of the 73 patients in our study, 11 patients were initially treated with endoscopy, and 62 proceeded directly to NUx. Mean follow-up from initial complete resection in delayed and immediate groups was 61 months and 58 months, respectively. Patient demographics and NUx pathologic data are shown in Table 1. Demographic data are from the time of NUx except for a history of bladder tumors. While significance was not obtained, patients in the delayed group tended to be older and had a greater CCI than patients in the immediate group (Table 1). From the time of initial complete resection, delayed NUx patients also tended to be older than immediate NUx patients (mean $=73 \pm 5.9$ years, $P=0.2174$ ) and had greater CCI (mean $=3.9 \pm 1.0, P=0.2321)$. A significantly greater percentage of delayed NUx patients previously had bladder tumors (Table 1).

Pathologic NUx data did not reveal significant differences in tumor size, grade, extent, location, or staging, although there was trend to larger tumors in the immediate NUx patients (Table 1). At the time of initial endoscopic biopsy, 7/10 $(70 \%)$ delayed NUx patients had low-grade disease, not significantly different from immediate NUx patients $(45 \%$, $P=0.1835$ ). Of these initial seven patients with low-grade disease, progression to high-grade disease occurred in three $(43 \%)$ at the time of delayed NUx. At diagnosis, disease was confined to the renal pelvis for all patients in the delayed group, but at NUx, disease was found in both renal pelvis and ureter in $7 / 11(64 \%)$.

Table 2 displays individual delayed NUx patient data. Of 11 patients, 5 (46\%) pursued endoscopic treatment electively. 
Table 1. Demographics and Tumor Characteristics at Nephroureterectomy, by Treatment Group

\begin{tabular}{|c|c|c|c|}
\hline Variable (no. in group) & Delayed nephroureterectomy & Immediate nephroureterectomy & P value \\
\hline All renal units (73) & 11 & 62 & \\
\hline \multicolumn{4}{|l|}{ Sex } \\
\hline Male (52) & $10(91 \%)$ & $42(68 \%)$ & \multirow[t]{2}{*}{0.1602} \\
\hline Female (21) & $1(9 \%)$ & $20(32 \%)$ & \\
\hline Age, years (mean $\pm S D)$ & $74.9 \pm 5.4$ & $69.0 \pm 10.6$ & 0.0688 \\
\hline $\mathrm{BMI}($ mean $\pm \mathrm{SD})$ & $27.0 \pm 3.6$ & $28.5 \pm 5.5$ & 0.5073 \\
\hline$<30$, nonobese $(47)$ & $8(73 \%)$ & $39(63 \%)$ & \multirow[t]{3}{*}{0.6887} \\
\hline $30-40$, obese $(23)$ & $3(27 \%)$ & $20(32 \%)$ & \\
\hline$>40$, morbidly obese ( 3 ) & $0(0 \%)$ & $3(5 \%)$ & \\
\hline ASA score (mean $\pm S D)$ & $2.5 \pm 0.5$ & $2.2 \pm 0.6$ & 0.3125 \\
\hline ASA 1-2 (49) & $6(54.5 \%)$ & $43(69 \%)$ & 0.4870 \\
\hline ASA 3-4 (24) & $5(45.5 \%)$ & $19(31 \%)$ & \\
\hline Age-adjusted CCI (mean \pm SD) & $4.2 \pm 1.3$ & $3.4 \pm 1.8$ & 0.1245 \\
\hline $0-3(38)$ & $4(36 \%)$ & $34(55 \%)$ & 0.3335 \\
\hline$\geq 4(35)$ & $7(64 \%)$ & $28(45 \%)$ & \\
\hline \multicolumn{4}{|l|}{ History of bladder tumors } \\
\hline No previous bladder tumors (57) & $4(36 \%)$ & $53(85.5 \%)$ & \multirow[t]{2}{*}{0.0014} \\
\hline Previous bladder tumors (16) & $7(64 \%)$ & $9(14.5 \%)$ & \\
\hline \multicolumn{4}{|l|}{ Pathology } \\
\hline \multicolumn{4}{|l|}{ Greatest tumor diameter $^{a}$} \\
\hline$<2 \mathrm{~cm}$, small $(12)$ & $4(40 \%)$ & $8(13 \%)$ & \multirow[t]{2}{*}{0.0607} \\
\hline$\geq 2 \mathrm{~cm}$, large (58) & $6(60 \%)$ & $52(87 \%)$ & \\
\hline \multicolumn{4}{|l|}{ Grade $^{\mathrm{a}}$} \\
\hline Low $(32)^{b}$ & $4(40 \%)$ & $28(45 \%)$ & \multirow[t]{2}{*}{0.9999} \\
\hline High (40) & $6(60 \%)$ & $34(55 \%)$ & \\
\hline \multicolumn{4}{|l|}{ Extent } \\
\hline Solitary (35) & $2(20 \%)$ & $33(53 \%)$ & \multirow[t]{2}{*}{0.0861} \\
\hline Multifocal (37) & $8(80 \%)$ & $29(47 \%)$ & \\
\hline \multicolumn{4}{|l|}{ Location } \\
\hline Renal pelvis $(64)^{c}$ & $10(100 \%)$ & $54(87 \%)$ & \multirow[t]{2}{*}{0.5891} \\
\hline Ureter (8) & $0(0.0 \%)$ & $8(13 \%)$ & \\
\hline \multicolumn{4}{|l|}{$\mathrm{T}$ stage } \\
\hline $\mathrm{T}_{0}(5)$ & $1(9.1 \%)$ & $4(6.5 \%)$ & \multirow[t]{6}{*}{0.3021} \\
\hline $\mathrm{T}_{\mathrm{a}}(35)$ & $3(27 \%)$ & $32(52 \%)$ & \\
\hline $\mathrm{T}_{\mathrm{is}}(2)$ & $1(9.1 \%)$ & $1(1.6 \%)$ & \\
\hline $\mathrm{T}_{1}(9)$ & $3(27 \%)$ & $6(9.7 \%)$ & \\
\hline $\mathrm{T}_{2}(3)$ & 0 & $3(4.8 \%)$ & \\
\hline $\mathrm{T}_{3}(19)$ & $3(27 \%)$ & $16(26 \%)$ & \\
\hline \multicolumn{4}{|l|}{ N stage } \\
\hline $0(68)^{\mathrm{d}}$ & $9(100 \%)$ & $59(95 \%)$ & \multirow[t]{2}{*}{$\mathrm{p}=0.9999$} \\
\hline $1(3)$ & 0 & $3(5 \%)$ & \\
\hline
\end{tabular}

Data expressed as mean \pm standard deviation for continuous data, or No. in group (\%) for nominal data.

asome data elements missing. For patients with $\mathrm{T}_{0}$, grade from initial biopsy is reported.

${ }^{\mathrm{b}}$ One patient in immediate NUx treatment group had a pathologic grade of LMP.

'Seven delayed NUx and nine immediate NUx patients with renal pelvic tumors also had ureteral tumors.

${ }^{\mathrm{d}}$ Two patients in the delayed group did not have sufficient lymph node dissection for $\mathrm{N}$ staging.

$\mathrm{SD}=$ standard deviation; $\mathrm{BMI}$ - body mass index; $\mathrm{ASA}=$ American society of anesthesiologists; $\mathrm{CCI}=\mathrm{Charlson}$ comorbidity index; $\mathrm{T}=$ tumor; $\mathrm{N}=$ node.

Of the remaining six patients, one had chronic renal insufficiency (CRI) with a preoperative creatinine level of $2.5 \mathrm{mg} /$ $\mathrm{dL}$, one had relative CRI with a creatinine level of $1.6 \mathrm{mg} / \mathrm{dL}$, two had solitary kidneys (previous nephrectomy for cancer), and two presented with bilateral UTUC.

Initial complete tumor resection for the 11 delayed NUx patients was obtained with 16 procedures (9 URS, 7 percutaneous). There were no complications during or after these procedures. Of all the delayed patients, eight entered surveillance at our institution and three with the referring urologist. Of the latter three, one was treated with mitomycin instillation via nephrostomy tube after initial resection in an attempt to increase the length of time between minimally in- vasive surveillance procedures, given the patient's poor overall health. The intervening procedures before NUx are unknown in the other two patients followed outside our institution. Of the eight patients we followed directly, there were 42 subsequent operations (37 URS, 5 percutaneous). On average, these eight patients underwent an operation every $3.7 \pm 1.0$ months while on active surveillance. There were three postoperative complications after surveillance procedures: One grade IVb and two grade IIIb; all occurred in patient 3 (Table 2).

For delayed NUx patients, median time to disease recurrence was 4.0 months, and median time to $\mathrm{NUx}$ was 10 months. After the first surveillance procedure, 5/11 (46\%) 


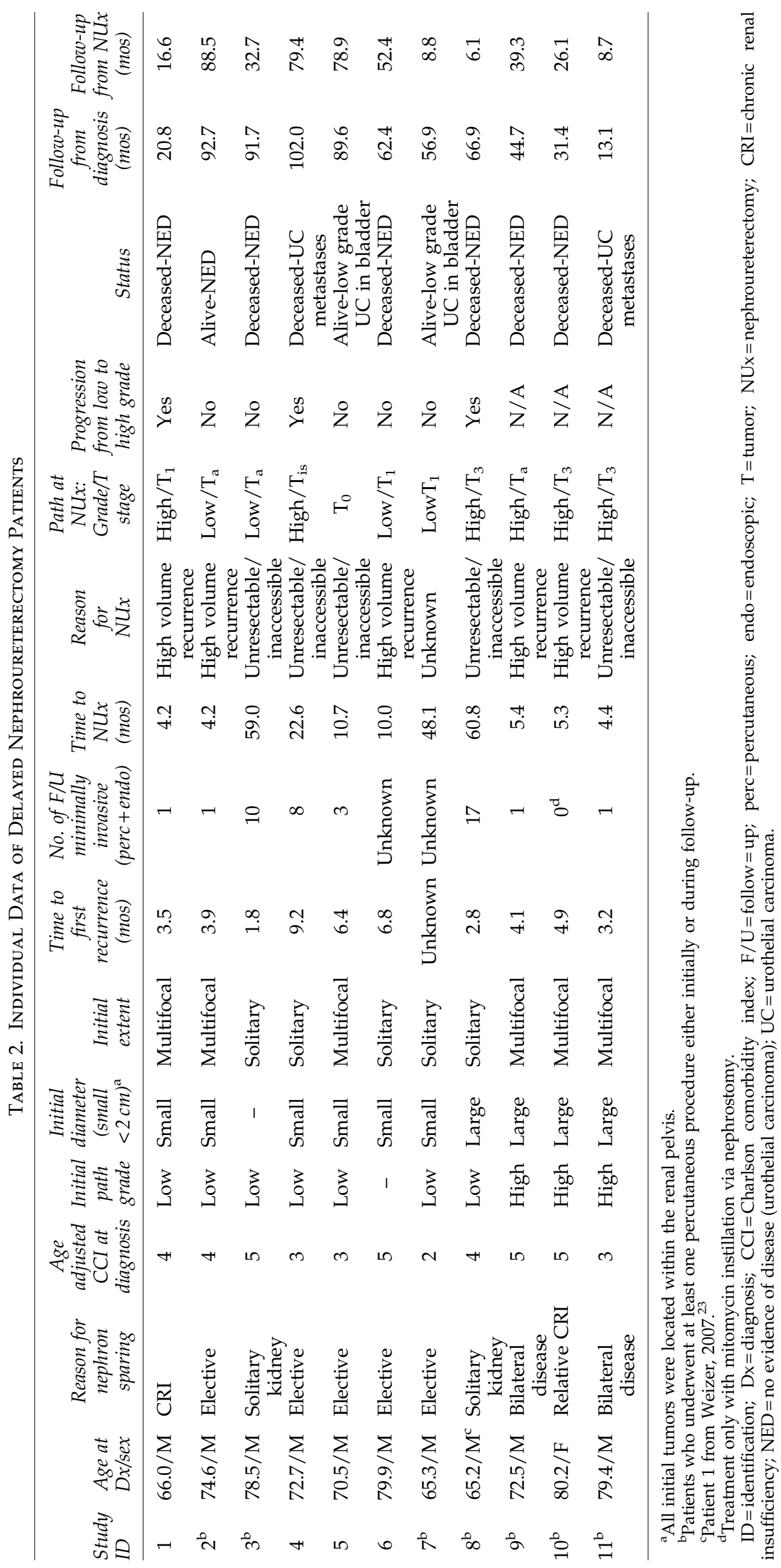


TAble 3. Laparoscopic Nephroureterectomy Operations

\begin{tabular}{|c|c|c|c|}
\hline Variable (no.) & $\begin{array}{c}\text { Delayed } \\
\text { nephroureterectomy }\end{array}$ & $\begin{array}{c}\text { Immediate } \\
\text { nephroureterectomy }\end{array}$ & P value \\
\hline $\begin{array}{l}\text { Operative time in minutes ( } 8 \text { delayed, } \\
60 \text { immediate) }\end{array}$ & $\begin{array}{l}278 \pm 130 \text { (range, } 127-551 \\
\text { median, } 235 \text { ) }\end{array}$ & $\begin{array}{c}253 \pm 72 \text { (range, } 117-457 \\
\text { median, } 246)\end{array}$ & 0.9242 \\
\hline Estimated blood loss in mL (8 delayed, 57 immediate) & $\begin{array}{l}231 \pm 180 \text { (range, } 50-500 \\
\text { median, } 188)\end{array}$ & $\begin{array}{l}284 \pm 241 \text { (range, } 50-1400 \\
\text { median, } 200)\end{array}$ & 0.5491 \\
\hline $\begin{array}{l}\text { Length of hospital stay in days (8 delayed, } \\
62 \text { immediate) }\end{array}$ & $\begin{array}{l}6 \pm 6(\text { range }, 2-21 \\
\text { median } 4)\end{array}$ & $\begin{array}{l}4 \pm 3 \text { (range, } 1-17 \\
\text { median, } 4)\end{array}$ & 0.7327 \\
\hline $\begin{array}{l}\text { Patients with intraoperative complications ( } 8 \text { delayed, } \\
62 \text { immediate) }\end{array}$ & $3(38 \%)$ & $7(11 \%)$ & 0.0812 \\
\hline $\begin{array}{l}\text { Patients with postoperative complications ( } 8 \text { delayed, } \\
62 \text { immediate) }\end{array}$ & $3(38 \%)$ & $18(29 \%)$ & 0.6889 \\
\hline Patients with any complications (8 delayed, 62 immediate) & $5(63 \%)$ & $22(36 \%)$ & 0.2457 \\
\hline $\begin{array}{l}\text { Clavien grade postoperative complications ( } 8 \text { delayed, } \\
62 \text { immediate) }\end{array}$ & & & 0.0699 \\
\hline I & 0 & $11(18 \%)$ & \\
\hline II & $1(13 \%)$ & $3(5 \%)$ & \\
\hline IIIa & 0 & $1(2 \%)$ & \\
\hline IIIlb & $1(13 \%)$ & $1(2 \%)$ & \\
\hline IVa & $1(13 \%)$ & 0 & \\
\hline $\mathrm{IVb}$ & 0 & $1(2 \%)$ & \\
\hline
\end{tabular}

Data expressed as mean \pm standard deviation for continuous data (range; median), or no. in group (\%) for nominal data.

tData from 2 patients who underwent nephroureterectomy with cystoprostatectomy, and from 1 patient who underwent nephroureterectomy at an outside institution, are excluded.

patients proceeded to NUx. Table 2 lists the reasons for proceeding to NUx. There was high volume recurrence in five patients at concern for significant risk of future progression, and endoscopically unresectable recurrence in five patients. Patient 7 underwent open NUx at an outside institution; whether the surgery was elective or for disease progression is unknown. Two patients ( 3 and 11, Table 2) underwent cystoprostatectomy for recurrent bladder disease during the same operation as NUx for unresectable UTUC. One of these operations was performed with a laparoscopic technique, the other with an open operation. The decision to proceed with open surgery reflected the operating urologist's preference rather than the history of multiple endoscopic procedures.

Table 3 compares perioperative parameters of NUx performed at our institution (without cystoprostatectomy) between eight delayed NUx patients and all immediate NUx patients. There were no significant differences in operative time, estimated blood loss, length of hospital stay, or complication rates between the two groups. Delayed NUx intraoperative complications included minor lacerations of the diaphragm in one patient and liver in one patient, both repaired without difficulty. One major complication of damage to the contralateral ureteral orifice necessitated significant surgical intervention to repair. Immediate NUx intraoperative complications included five minor small bowel lacerations with simple repairs, one major small bowel laceration necessitating open repair, and 1 major spleen laceration necessitating cautery repair. Clavien graded postoperative complications for both groups are listed in Table 3 .

Figure 1 displays Kaplan-Meier survival curves that compare treatment groups. There was no significant difference in OS from date of first complete resection (Fig. 1A) with 5-year survivals in the delayed and immediate group of $64 \%$ and $59 \%$, respectively. No significant differences were found in the 5-year metastasis-free survivals from initial treatment for delayed and immediate NUx, 77\% and 73\%, respectively (Fig. 1B), and of CSS, $91 \%$ and $80 \%$, respectively (Fig. 1C).

\section{Discussion}

We and others showed previously that conservative management for low-grade UTUC is equivalent to immediate NUx when patients are grouped by initial treatment methods. $^{7-9}$ This current report suggests that failed conservative management does not significantly affect survival, compared with immediate NUx, when appropriate triggers for delayed NUx are applied.

Similar studies that compare patients with delay to extirpative surgery are relatively rare in the current literature, and often there is substantial heterogeneity in the treatment methods between initial diagnosis and definitive resection. Most analogous to our study, Boorjian and associates ${ }^{18}$ reported on 12 patients with low-grade disease and found that a mean delay of 196 days (6.5 mos) to NUx after ureteroscopic biopsy and laser ablation did not adversely affect disease status at a mean follow-up of 38.7 months compared with patients who had immediate NUx. Sundi and colleagues ${ }^{19}$ recently compared 54 patients who delayed surgical management of UTUC more than 3 months from diagnosis with 186 patients who underwent surgery less than 3 months from diagnosis; $94 \%$ of procedures were NUx, with a mean time to surgery in the delayed group of 14.4 months. Of the delayed group, $50 \%$ underwent neoadjuvant chemotherapy, 17\% (nine patients) delayed NUx for endoscopic management, and the remaining patients were delayed by referral time and patient comorbidities. High-grade disease was found in approximately $80 \%$ of both groups, yet there was no significant difference between OS or CSS when all patients were compared. More relevant to our study, no difference was found in OS or CSS when patients receiving neoadjuvant chemotherapy were excluded. 


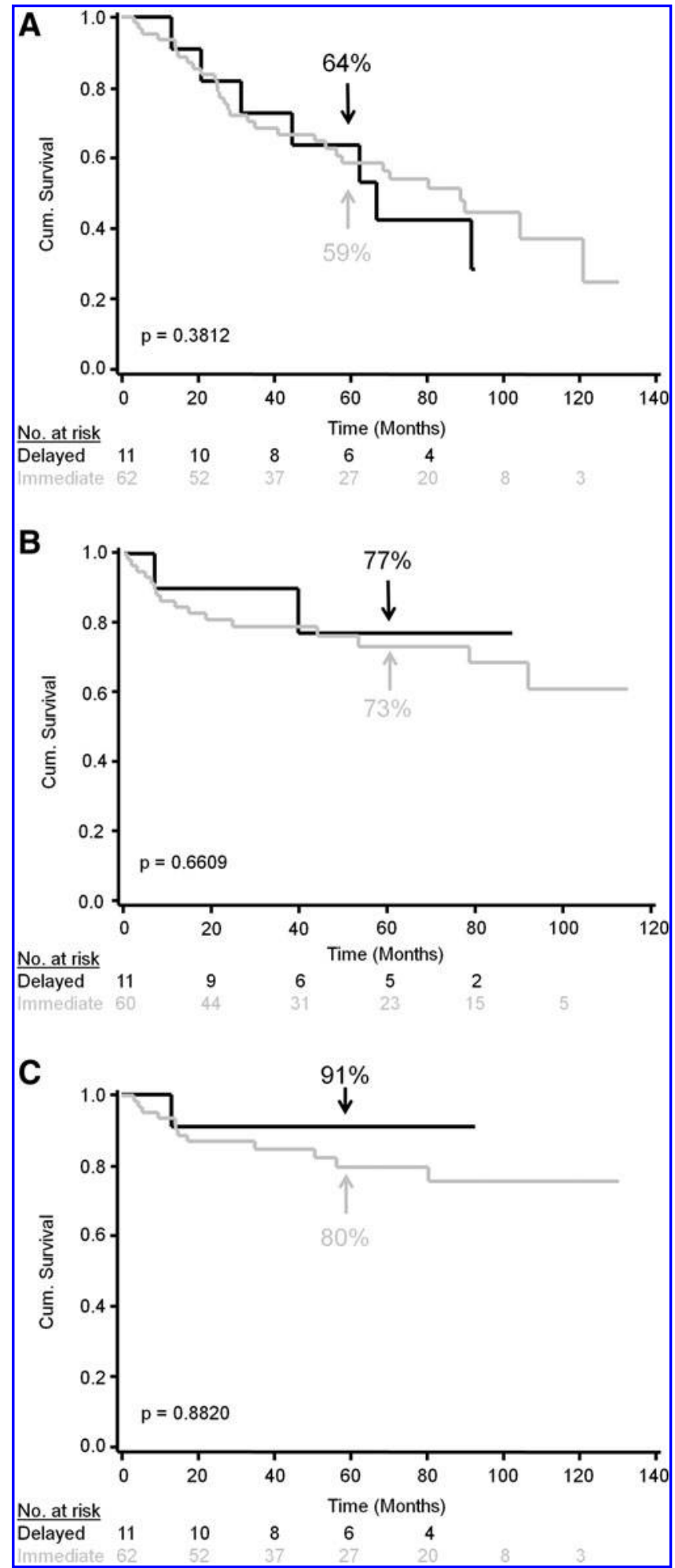

FIG. 1. Survival curves that compare immediate with delayed nephroureterectomy. Overall survival from first complete resection (A), metastasis-free survival (B), and cancer-specific survival (C). Five-year survival estimates indicated by arrows. Curves were truncated when two or fewer patients were at risk. Cum =cumulative
Waldert and coworkers ${ }^{20}$ compared 41 patients, of whom only 7 had previous endoscopic procedures, who delayed NUx more than 3 months (median 110 days) with 146 patients who underwent NUx within 3 months of UTUC diagnosis. High-grade disease was found in $64 \%$ and $76 \%$ of immediate and delayed groups, respectively. CSS did not differ with delayed NUx, despite an increase in pathologic T stage and lymph node involvement.

While the heterogeneity of these studies makes specific comparisons challenging, these reports are consistent with our findings that a trial of endoscopic management does not worsen survival in patients with UTUC.

Our results and those of others are critical in determining the relative safety of attempting endoscopic management, especially in light of the reported risks of delaying cystectomy in patients with clinical stage $\mathrm{T}_{2}$ or higher bladder cancer. ${ }^{21,22}$ In two studies, OS was significantly worse when patients delayed surgery more than 3 months from diagnosis, and CSS was worse in one study. Most endoscopically treated UTUC patients are similar to $\mathrm{pT}_{\mathrm{a}}$ bladder cancer patients, where superficial disease can frequently be treated effectively by transurethral resection, reserving extirpative surgery (cystectomy) for patients with invasive disease progression. The previously mentioned studies of Sundi and associates ${ }^{19}$ and Waldert and colleagues ${ }^{20}$ both reported a majority of patients with high-grade disease in both delayed and immediate groups. While the heterogeneity of the UTUC groups makes comparisons less precise than in the bladder cancer studies, these results may suggest that there is less of an impact to delay in UTUC. There is likely a selection bias toward less aggressive disease in delayed definitive management, however, despite high-grade pathology.

It is notable that while survival outcomes appear to be equivalent in delayed extirpative surgery, pathologic upgrading does occur in some patients. In our study, 3/7 patients experienced progression from low- to high-grade carcinoma. In other studies, $33 \%$ of 12 patients ${ }^{18}$ and $71 \%$ of 7 patients ${ }^{8}$ progressed from low- to high-grade disease on NUx after initial endoscopic management. Because endoscopic management failed for these patients, there is a bias toward more aggressive disease; however, the possibility of disease progression must be accepted when patients elect conservative management. ${ }^{23}$

Patients must also be willing to undergo frequent minimally invasive procedures during conservative management, but no differences were found in perioperative parameters and postoperative courses when HALS NUx is delayed. In a large study of 6078 NUx performed for nonmetastatic UTUC, Jeldres and coworkers ${ }^{24}$ found a 90 -day perioperative mortality of $4.4 \%$ in patients of all ages, $4.4 \%$ in patients 70 to 79 years old, and $8.3 \%$ in patients $>80$ years; the most common cause of death was renal insufficiency (45\%). NUx techniques were not reported, but given the nonstandardized NUx method in UTUC, this statistic is critical when elderly patients select disease management. Similar large population statistics for endoscopic procedures were not found in the current literature; however, they are anecdotally considered safer regarding perioperative mortality.

Our report's limitations include those intrinsic to retrospective studies. Nonrandomized patients and bias toward small low-grade disease in patients who elected trials of endoscopic management are possible confounding factors. The 
delayed group was also limited in size and heterogeneous in reasons for nephron-sparing management. The small size of the delayed group prohibited meaningful multivariate analysis, and limits the power of our study. To our knowledge, however, we are one of the first to report long-term outcomes exclusively comparing patients who failed endoscopic management with those who underwent immediate NUx for UTUC. The homogeneity of treatment method before definitive surgery, despite heterogeneity in patient population, is a strong point of this report.

There is increasing evidence that nephron-sparing management of low-grade UTUC is at worst equivalent to immediate NUx. ${ }^{7-9}$ We have shown that failing endoscopic management and proceeding to NUx does not affect OS and cancer-related outcomes. Large multicenter prospective trials with standardized protocols must be performed to confirm that there is no harm in electing endoscopic therapy, and to establish common practices guidelines for UTUC treatment. Until then, it is our experience that patients with small lowgrade disease may elect a trial of conservative management knowing that if disease progression necessitates NUx, systemic long-term cancer progression and OS will not be adversely affected.

\section{Conclusions}

Our study suggests that long-term OS and cancer-related outcomes do not differ when patients attempt a trial of endoscopy and delay NUx for UTUC. In cases of resectable low-grade disease, initiating endoscopic monitoring is an alternative to immediate NUx. We still hold that high-grade disease should undergo immediate extirpative resection when there are no indications for nephron sparing, but endoscopy can temporarily maintain the renal unit in patients with imperative indications.

\section{Disclosure Statement}

Dr. Roberts is an adviser, consultant, and owner with Histosonics. For the remaining authors, no competing financial interests exist.

\section{References}

1. Flanigan R. Urothelial tumors of the upper urinary tract. In: Wein A, Kavoussi L, Novick A, Partin A, Peters C, eds. Campbell-Walsh Urology. 9th ed. Philadelphia, PA: Elsevier Saunders, 2007, pp 1638-1652.

2. Margulis V, Shariat SF, Matin SF, et al. Outcomes of radical nephroureterectomy: A series from the Upper Tract Urothelial Carcinoma Collaboration. Cancer 2009;115:12241233.

3. Huffman JL, Bagley DH, Lyon ES, et al. Endoscopic diagnosis and treatment of upper-tract urothelial tumors. A preliminary report. Cancer 1985;55:1422-1428.

4. Streem SB, Pontes EJ. Percutaneous management of upper tract transitional cell carcinoma. J Urol 1986;135:773-775.

5. Krambeck AE, Thompson RH, Lohse CM, et al. Imperative indications for conservative management of upper tract transitional cell carcinoma. J Urol 2007;178:792-797.

6. Deligne E, Colombel M, Badet L, et al. Conservative management of upper urinary tract tumors. Eur Urol 2002;42: $43-48$.
7. Gadzinski AJ, Roberts WW, Faerber GJ, Wolf JS Jr. Longterm outcomes of nephroureterectomy versus endoscopic management for upper tract urothelial carcinoma. J Urol 2010;183:2148-2153.

8. Lucas SM, Svatek RS, Olgin G, et al. Conservative management in selected patients with upper tract urothelial carcinoma compares favourably with early radical surgery. BJU Int 2008;102:172-176.

9. Roupret M, Hupertan V, Traxer O, et al. Comparison of open nephroureterectomy and ureteroscopic and percutaneous management of upper urinary tract transitional cell carcinoma. Urology 2006;67:1181-1187.

10. Sowter SJ, Ilie CP, Efthimiou I, Tolley DA. Endourologic management of patients with upper-tract transitional-cell carcinoma: Long-term follow-up in a single center. I Endourol 2007;21:1005-1009.

11. Thompson RH, Krambeck AE, Lohse CM, et al. Endoscopic management of upper tract transitional cell carcinoma in patients with normal contralateral kidneys. Urology 2008;71: 713-717.

12. Suh RS, Faerber GJ, Wolf JS Jr. Predictive factors for applicability and success with endoscopic treatment of upper tract urothelial carcinoma. J Urol 2003;170:2209-2216.

13. Wolf JS Jr, Dash A, Hollenbeck BK, et al. Intermediate followup of hand assisted laparoscopic nephroureterectomy for urothelial carcinoma: Factors associated with outcomes. J Urol 2005;173:1102-1107.

14. Keeley FX, Kulp DA, Bibbo M, et al. Diagnostic accuracy of ureteroscopic biopsy in upper tract transitional cell carcinoma. I Urol 1997;157:33-37.

15. Williams SK, Denton KJ, Minervini A, et al. Correlation of upper-tract cytology, retrograde pyelography, ureteroscopic appearance, and ureteroscopic biopsy with histologic examination of upper-tract transitional cell carcinoma. I Endourol 2008;22:71-76.

16. Charlson ME, Pompei P, Ales KL, MacKenzie CR. A new method of classifying prognostic comorbidity in longitudinal studies: Development and validation. J Chronic Dis 1987;40:373-383.

17. Dindo D, Demartines N, Clavien PA. Classification of surgical complications: A new proposal with evaluation in a cohort of 6336 patients and results of a survey. Ann Surg 2004;240:205-213.

18. Boorjian $\mathrm{S}, \mathrm{Ng} \mathrm{C}$, Munver $\mathrm{R}$, et al. Impact of delay to nephroureterectomy for patients undergoing ureteroscopic biopsy and laser tumor ablation of upper tract transitional cell carcinoma. Urology 2005;66:283-287.

19. Sundi D, Svatek RS, Margulis V, et al. Upper tract urothelial carcinoma: Impact of time to surgery. Urol Oncol Sep 23 2010. E-pub ahead of print.

20. Waldert M, Karakiewicz PI, Raman JD, et al. A delay in radical nephroureterectomy can lead to upstaging. BJU Int 2009;105:812-817.

21. Lee CT, Madii R, Daignault $S$, et al. Cystectomy delay more than 3 months from initial bladder cancer diagnosis results in decreased disease specific and overall survival. J Urol 2006;175:1262-1267.

22. Sánchez-Ortiz RF, Huang WC, Mick R, et al. An interval longer than 12 weeks between the diagnosis of muscle invasion and cystectomy is associated with worse outcome in bladder carcinoma. J Urol 2003;169:110-115.

23. Weizer AZ, Faerber GJ, Wolf JS Jr. Progression of disease despite good endoscopic local control of upper tract urothelial carcinoma. Urology 2007;70:469-472. 
24. Jeldres $C$, Sun $M$, Isbarn $H$, et al. A population-based assessment of perioperative mortality after nephroureterectomy for upper-tract urothelial carcinoma. Urology 2010;75: 315-320.

Address correspondence to: J. Stuart Wolf, Jr, M.D. Department of Urology University of Michigan 3875 Taubman Center 1500 East Medical Center Drive Ann Arbor, MI 48109-5330

E-mail: wolfs@umich.edu

\section{Abbreviations Used}

$\mathrm{CCI}=$ Charlson comorbidity index

$\mathrm{CRI}=$ chronic renal insufficiency

$\mathrm{CSS}=$ cancer-specific survival

$\mathrm{CT}=$ computed tomography

$\mathrm{HAL}=$ hand-assisted laparoscopic

HALS $=$ hand-assisted laparoscopic surgery

MRI = magnetic resonance imaging

$\mathrm{NUx}=$ nephroureterectomy

OS $=$ overall survival

$\mathrm{URS}=$ ureteroscopy

$\mathrm{UTUC}=$ upper tract urothelial carcinoma 